\title{
Influence of the near-surface water film thickness on the characteristics and conditions of water-coal fuel particles inflammation
}

\author{
Samen Syrodoy, ${ }^{1,}$, Roman Taburchinov ${ }^{1}$, and Irina Mikhaylova ${ }^{2}$ \\ ${ }^{1}$ National Research Tomsk Polytechnic University, 634050 Tomsk, Russia \\ ${ }^{2}$ Tomsk State University of Architecture and Building, 634003 Tomsk, Russia
}

\begin{abstract}
The results of experimental studies of thermal pretreatment processes complex and inflammation of water coal fuel's particles (WCF), which surface is covered with water film, have been presented there. The research has been carried out with using of three fuel types (cannel coal, coal B and filter cake): they have essentially different thermo physical characteristics. The results of our studies have been shown that the dynamics of the near-surface water film evaporation and fuel inflammation depends significantly on coal type. It has also been analyzed the influence of water layer thickness on the conditions of WCF particles inflammation. It has been established the time of water film evaporation is about $70 \%$ due to the whole induction period.
\end{abstract}

\section{Introduction}

Turbulent dynamics of pricing for main utilities (oil and natural gas) [1-3] forms the certain conditions to apply the alternative types of fuel (for example, coal) in the world and native power economy. However, the main problems, connected with coal combustion in massfired refuse power boilers, haven't been solved yet. To latter we include, first of all, emissions of nitrogen oxides $\left(\mathrm{NO}_{\mathrm{x}}\right)$ and sulfur $\left(\mathrm{SO}_{\mathrm{x}}\right)$, formed during high-temperature oxidation of coal fuel in the combustion chamber. Nowadays the developed systems of clean coal combustion (for example, with the application of the circulating fluidized bed [4], the vortex principle [5], the plasma systems [6], etc.) haven't been used widely due to the high price of the auxiliary boiler equipment. At the present time, the technology of coal combustion in the form of especially made fuel compositions on the foundation of coalwater slurry is the main perspective technical solution for using of coal fuel.

To date, there are a number of objectives and subjective reasons that significantly impede the introduction of WCF in the energy sector. As a rule, the main part of them is connected with the technology process, but has no connections with the fundamental problems of energy science.

The most acute problem is the development of physical theory and its mathematics base of WCF drops inflammation and combustion processes. The latter is connected with the difficulties of the heat transmission modeling in the essential heterogeneous structures of

*Corresponding author: syrodoy@tpu.ru 
water-coal fuel. This is due to the fact that evaporation of water is the most influential for the thermal preparation process. As it is known [7], the phase transformation processes usually occur with a large endothermic effect (up to $2.5 \mathrm{MJ} / \mathrm{kg}$ ) in a very narrow and constantly moving zone (the front of the phase transition). The mathematical modeling is significantly complicated by the fact that during the spraying of fuel with a fairly high probability it is possible to form both partially dried and excessively watered particles of water-coal fuel [8]. The latter particles are a drop, the surface of which is covered with a water film. As it has been established earlier [9-11], such a liquid layer can have a significant effect on the dynamics of ignition of the WCF particle. However, the estimates of the influence of the thickness of this layer on the characteristics and conditions of ignition have not been carried out yet.

The aim of our studies is to investigate the inflammation processes of water-coal fuel particles in the conditions of the intensive radioactive convection heating with the variation of water layer thickness.

\section{Experiment}

The experimental studies have been carried out on the stand which is the same to the installation according to the field recording procedure [12]. The fuel particle (covered with the water film) has been fastened on the suck board and has been put in into the hollow ceramic chamber, heated to the temperature $T_{e}=1270 \mathrm{~K}$ with the help of coordinate remote controlled device. The video fixation of the heat and mass transfer processes' dynamics has been realized with high-speed video camera Photron FASTCAM CA4 5. The period time of the beginning of heating effect (the moment of putting the fuel particle into the piston chamber) to the beginning of the firing (appearance of flame) has been considered as the time of combustion delay $\left(\mathrm{t}_{\mathrm{ign}}\right)$. The sizes of the particles are varied within the limits of $1.5<\delta<3.5 \cdot 10^{-3} \mathrm{M}$. The systematic error of the main measurable parameters dimensioning has been no more than $5 \%$. The confidence interval of this definition $t_{\text {ign }}$ with the level of confidence 0.95 has not exceeded $18 \%$.
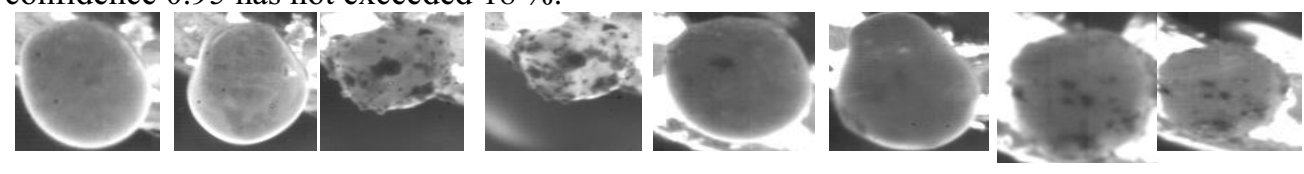

$$
\begin{array}{cccccccc}
a & b & c & d & a & b & c & d \\
t=0 \mathrm{~s} & t=1.01 \mathrm{~s} & t=2.51 \mathrm{~s} & t=4.08 \mathrm{~s} & t=0 \mathrm{~s} & t=0.78 \mathrm{~s} & t=2.42 \mathrm{~s} & t=3.87 \mathrm{~s}
\end{array}
$$

Fig. 1a. The typical video frames of the particles inflammation of water-coal fuel on the foundation of coal D covered with the water film.

Fig. 1b. The typical video frames of the particles inflammation of water-coal fuel on the foundation of coal B covered with the water film.



Fig.1c. The typical video frames of the particles inflammation of water-coal fuel on the foundation of the filter-KEK covered with the water film. 


\section{The results of the experimental studies}

The typical video frames of the particles inflammation and firing processes (diameter $\delta \approx 2.5 \cdot 10^{-3} \mathrm{M}$ ) of the water-coal fuel made from the variant kinds of coal with different metamorphism intensity are presented in the figures 1 (a, b, c): cannel coal (fig. 1 a), brown coal (fig.1 b) and filter cake (fig.1 c), covered with water film at the temperature environment $T_{e}=1273 K$. The analysis of the frames has shown the whole period of thermal treating of fuel we could relatively divide into a raw of some succeeding stages. At first (video frame a) is a water-coal aggregation covered with water film. As a result, we have evaporation process that has been instigated due to the thermal influence, when this happens we could observe the change of the size and form of the fuel drop (fig. b). The last has been caused with boiling water. There is dehydration of the main fuel layer and coal inflammation after the disposal of water film. It can be noted that the evaporation period of the water film is approximately $70 \%$ of the total ignition delay time. Most likely this is due to the fact that when the water film boils, the heating of the main fuel layer to the phase transition temperature occurs. Accordingly, the subsequent dehumidification occurs much faster than for the fuel particles without such a layer.

There are the time dependences of the water film evaporation at the fig.2 and the ignition delays of water film ( $\left.\mathrm{t}_{\mathrm{v}}\right)$ of the water-coal fuel particles based on the cannel coal at the exterior temperature in the different water layers' thickness. The analysis of the dependences shows that water film influences significantly on the inflammation conditions. So the change of water film thickness from 0.2 to 0.7 leads to the double increasing of the induction period (from 4.5 to 8 seconds) at the exterior temperature $\left(\mathrm{T}_{\mathrm{e}}\right)$. And as it is noted previously the time of water film evaporation is about $60 \%$ from $t_{i}$. The last, most likely, is determined with the heating up of the main coal-water agglomerate in the near-surface water layer evaporation process to the water boiling temperature. Consequently, the following WCF drop dehydration takes place more quickly than the particles without water film.

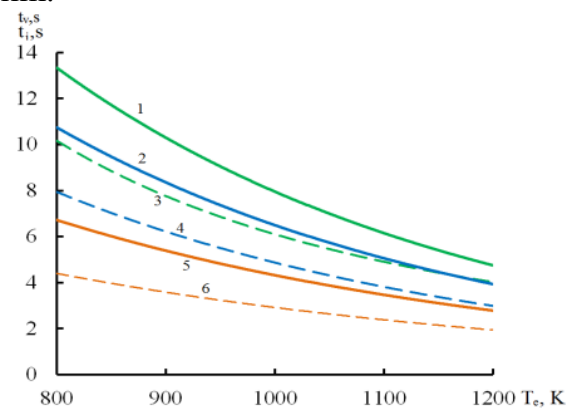

Fig. 2. Time dependence of the full water film evaporation and ignition delay of water film with diameter: $\mathrm{d}=2 \cdot 10^{-3} \mathrm{~m}$ from the temperature, with water film: $1,3-\delta \approx 0.7 \mathrm{~mm}$; $2,4-\delta \approx 0.4 \mathrm{~mm} ; 5,6-\delta \approx 0.2 \mathrm{~mm}$. 1, 2, 5 - time of ignition delay $\left(\mathrm{t}_{\mathrm{i}}\right) ; 3,4,6$ - time of ignition delay of water film $\left(\mathrm{t}_{\mathrm{v}}\right)$.

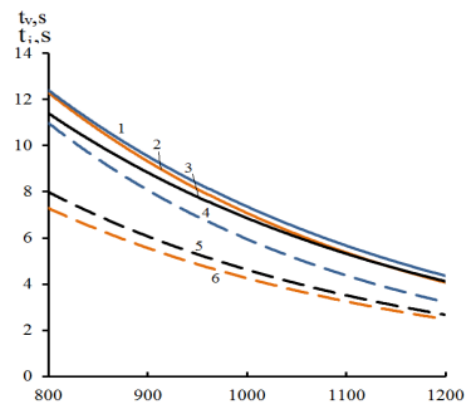

Fig. 3. Time dependence of the full water film evaporation and ignition delay of water film with diameter $\mathrm{d}=2 \cdot 10^{-3} \mathrm{M}$ from the temperature. WCF have been done from: 1,4 - filter cake; 2,6 brown coal ; 3,5 - channel coal. 1, 2, 3-dwell time of implantation $\left(\mathrm{t}_{\mathrm{i}}\right) ; 4,5,6$ - time of ignition delay of water film $\left(\mathrm{t}_{\mathrm{v}}\right)$.

The temporal characteristics of the evaporation processes of the near-surface water layer and the ignition of water-coal fuel particles based on coals of different grades (long-flame, brown and filter-KEK), with a film thickness of $0.5 \mathrm{~mm}$ are compared in the figure 3 . The analysis of the dependences shows that the delay time of all three fuel types is practically 
identical, while the terms of $t_{v}$ differ markedly. Perhaps it is connected with essentially different thermo physical characteristics (thermal conduction, heat capacitance and density) of the main fuel component (coal).

Probably the great amount of the metal and mineral existence in the structure of filterKEK leads to the increasing its heat capacitance, because of it the heating up and water film evaporation takes place slower due to the heat efflux in the fuel structure. Also the dependences at the figure 4 confirm the noted the thesis (using at the description figure 2) about the near-surface water film time evaporation is the most part of the thermal pretreatment period. It is connected with the heating up of the main fuel layer at the water film evaporation.

\section{Conclusion}

The results of the experimental studies have been established the main time characteristics of the thermal pretreatment processes and the particle inflammation of water-coal fuel, which surface is covered with thin watered layer. It has been improved that the time of the water film evaporation could take about $60 \%$ from the whole induction period. The hypothesis has been put forward that when the near-surface water layer evaporates, the main fuel mass is heated to the evaporation temperature. As a result, the subsequent dehydration of the main fuel layer occurs much faster than when the WCF particles are ignited without a water film. Accordingly, it can reasonably be assumed that in order to ensure the steady ignition of drops of water-coal fuel in the furnace space, it is necessary to organize zones of the constant recycling of the WCF flame.

The work was supported by the scientific schools grant NSH-7538-2016.8.

\section{References}

1. A. Demirbas, Prog. Energy Combust. Sci. 31, (2005)

2. S.H. Hosseini, G.H. Shakouri, Energy Policy. 91, (2016)

3. H.B. Ghassan, H.R. AlHajhoj, Applied Energy, 169, (2016)

4. J.K. Martin, J. A. Faaij, Prog. Energy Combust. Sci. 33, (2007)

5. K.Y. Orlova, B.V. Lebedev, MATEC Web Conf. 92, (2017)

6. V.E. Messerle, E.I. Karpenko, A.B. Ustimenko, Fuel, 126, (2014)

7. V.V. Salomatov, G.V. Kuznetsov, S.V. Syrodoy, N.Y. Gutareva, Appl. Therm. Eng. 106, (2016)

8. S.E. Nydick, F. Prochet, H.A. Steiger, J. Eng. Gas Turbines Power, 109, (1987)

9. A.V. Zakharevich, G.V. Kuznetsov, V.V. Salomatov, P.A. Strizhak, S.V. Syrodoy, Combustion, Explosion, and Shock Waves, 52, (2016)

10. S.V. Syrodoy N.Y. Gutareva, R.I. Taburchinov, MATEC Web Conf. 72, (2016)

11. S.V.Syrodoy, N.Y. Gutareva, R.I. Taburchinov, MATEC Web Conf. 72, (2016)

12. V.V. Salomatov, G.V. Kuznetsov S.V. Syrodoy, N.Y. Gutareva, Appl. Therm. Eng. 106, (2016) 